\title{
Exploring the Reactivity of $\alpha$-Lithiated Aryl Benzyl Ethers: Inhibition of the [1,2]-Wittig Rearrangement and Revisited Mechanistic Proposal
}

\author{
Rocío Velasco, ${ }^{[a]}$ Carlos Silva-López ${ }^{[b]}$ Olalla Nieto-Faza, ${ }^{*[b]}$ and Roberto Sanz ${ }^{*[a]}$
}

\begin{abstract}
By a careful control of reaction temperature, treatment of aryl benzyl ethers with tBuLi selectively leads to $\alpha$-lithiation, generating stable organolithiums which can be directly trapped with a variety of selected electrophiles, before they can undergo the expected [1,2]-Wittig rearrangement. This rearrangement has been deeply studied, both experimental and computationally, with aryl $\alpha$ lithiated benzyl ethers bearing different substituents at the aryl ring. The obtained results support the competence of a concerted anionic intramolecular addition / elimination sequence and a radical dissociation / recombination sequence for explaining the tendency of migration for aryl groups. The more favored rearrangements are found for substrates with electron poor aryl groups that favor the anionic pathway.
\end{abstract}

\section{Introduction}

The [1,2]-Wittig rearrangement, ${ }^{[1]}$ first reported by Wittig and Löhmann in the reactions of benzylic ethers with $\mathrm{PhLi},{ }^{[2]}$ involves the $[1,2]$-alkyl migration from an oxygen atom to an $\alpha$-carbanion center leading to lithium alkoxides. The intermediate $\alpha$-oxygen carbanions are usually generated by deprotonation of the corresponding ether or by tin-lithium exchange. ${ }^{[3]}$ These $\alpha$ oxygenated organolithiums ${ }^{[4]}$ are generally unstable, undergoing either $\alpha$-elimination or Wittig rearrangements. Although different mechanisms have been proposed for the [1,2]-Wittig rearrangement, ${ }^{[5]}$ the most well-recognized one that better accommodates the experimental results (migratory ability of $R$ groups increases with the stability order of the corresponding $\mathrm{R}^{*}$ ), involves two steps: radical pair dissociation and subsequent recombination of the radical and radical anion fragments to afford a lithium alkoxide (Scheme 1, eq 1). ${ }^{[1]}$ Whereas in most of the reported examples migrating groups are alkyl and benzyl, ${ }^{[6]}$ the related shifts of vinyl ${ }^{[7]}$ and aryl ${ }^{[8]}$ groups are less common. For the migration of aryl groups in aryl benzyl ethers Eisch et al. established that the radical anionic mechanism

[a] R. Velasco, Prof. Dr. R. Sanz

Área de Química Orgánica, Departamento de Química

Facultad de Ciencias, Universidad de Burgos

Pza. Misael Bañuelos s/n, 09001-Burgos (Spain)

E-mail: rsd@ubu.es

[b] Dra. O. Nieto-Faza, Dr. C. Silva-López

Departamento de Química Orgánica

Universidade de Vigo, Campus As Lagoas

32004-Ourense, Galicia (Spain)

E-mail: faza@uvigo.es

Supporting information for this article is given via a link at the end of the document. previously proposed for $\alpha$-alkoxyorganolithiums is also operating. ${ }^{[8 a]}$ Moreover, these authors clearly rejected an alternative intramolecular nucleophilic substitution mechanism involving a bridged aryl intermediate (Scheme 1, eq 2). However, more recently Schlosser and Strunk have studied the Wittig rearrangement of lithiated allyl aryl ethers (Scheme 1, eq 3), suggesting an intramolecular addition / elimination process that accounts for the observed lesser tendency of the 4-t-butylphenyl group to undergo migration in comparison with the parent phenyl group ( 10 times slower) ${ }^{[9]}$ In addition, it should also be considered that due to the higher strength of aromatic $\mathrm{C}-\mathrm{H}$ bonds, it is known that phenyl radical is significantly less stable than alkyl radicals, including methyl one (radical stabilization energy for phenyl radical $=+32.9 \mathrm{~kJ} \mathrm{~mol}^{-1}$ vs. $0 \mathrm{~kJ} \mathrm{~mol}^{-1}$ for methyl or $-26.8 \mathrm{~kJ} \mathrm{~mol}^{-1}$ for isopropyl). ${ }^{[10]}$

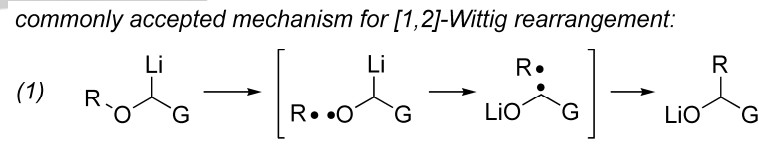

proposed and rejected mechanisms for [1,2]-Wittig rearrangement of aryl benzyl ethers: ${ }^{[7 a]}$

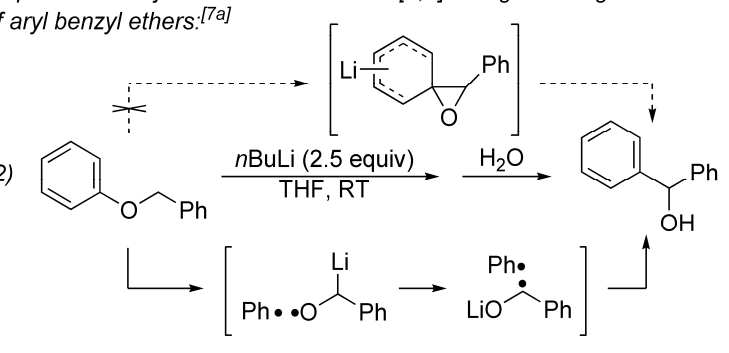

alternative mechanism for [1,2]-Wittig rearrangement of allyl aryl ethers: ${ }^{8]}$

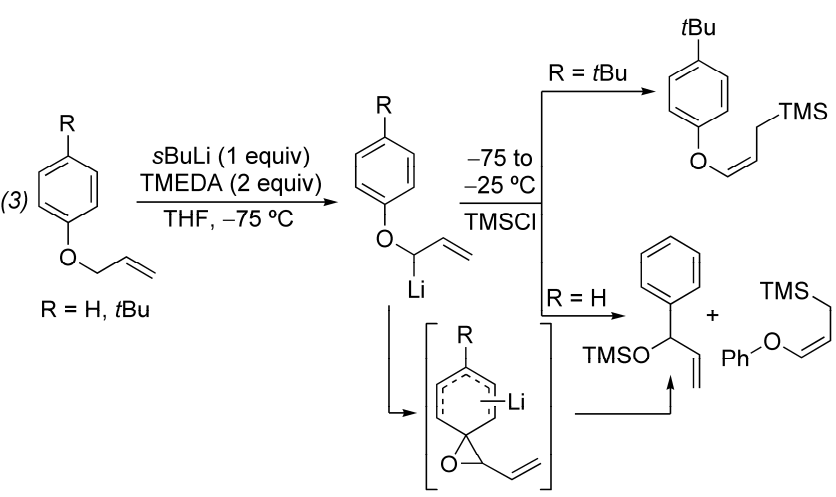

Scheme 1. Previous work: Mechanistic proposals for [1,2]-Wittig rearrangement of aryl ethers. 
On the other hand, it is known that if $\mathrm{G}$ is vinyl or aryl, i.e. lithiated allyl or benzyl ethers (Scheme 1, eq 1), then the migrating group may be benzylic, secondary or primary alkyl (but not methyl). Due to the reluctance of the methyl group to migrate $\alpha$-methoxy arylmethyl carbanions can be trapped with electrophiles. ${ }^{[11]}$ The suppression of the Wittig rearrangement in other substrates apart from benzyl methyl ethers, ${ }^{[12]}$ would allow the selective $\alpha$-functionalization of benzyl ethers expanding the synthetic potential of their $\alpha$-carbanions. However, little is known about the nucleophilic additions or substitution reactions of $\alpha$ oxybenzyllithiums.

Following our research in this field ${ }^{[13]}$ we have previously reported that $\alpha$-lithiobenzyl $o$-lithiophenyl ethers, generated from benzyl 2-halophenyl ethers by halogen-lithium exchange and further $\alpha$-lithiation, do not suffer Wittig rearrangement allowing their trapping with carboxylic esters and leading to benzo[b]furan derivatives(Scheme 2) ${ }^{[14]}$ With all these results in mind, we have recently described that the Wittig rearrangement in $\alpha$-lithiobenzyl phenyl ether can be suppressed by a careful control of the reaction temperature, allowing the intermediate organolithium to be functionalized prior to suffering the expected [1,2]-Wittig rearrangement (Scheme 2). ${ }^{[15]}$ Herein, we wish to report a detailed study about the $\alpha$-lithiation of a wide variety of aryl benzyl ethers in order to collect new data, both experimental and computationally, to find out which of the proposed mechanisms for aryl migration is operating. In addition, and considering the underexplored reactivity of $\alpha$-lithiobenzyl ethers, we have also studied deeply their reactions with different electrophiles.
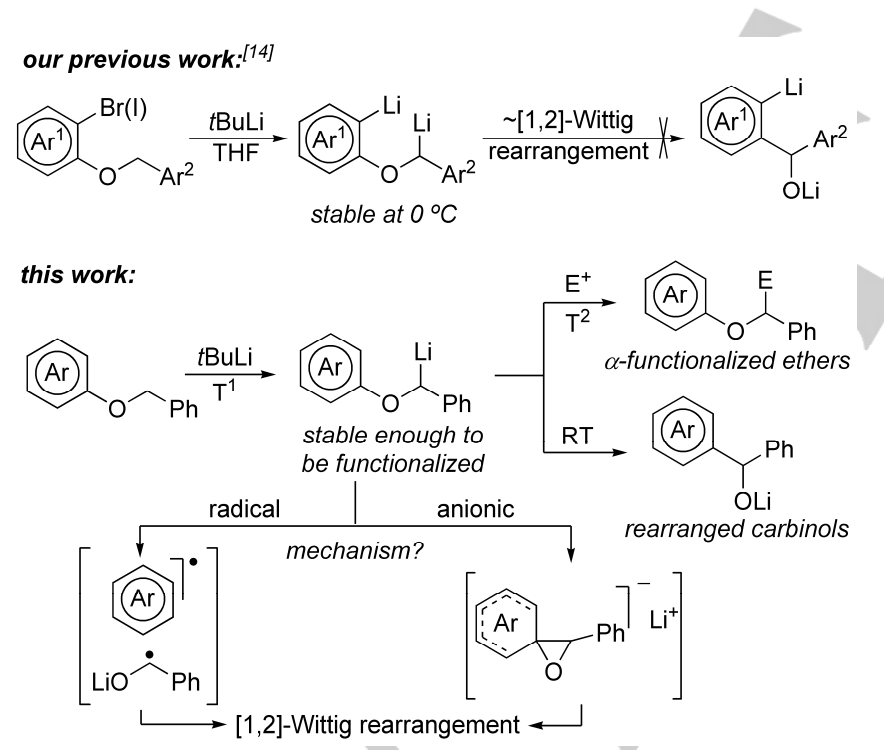

Scheme 2. This work: Inhibition and mechanistic studies for the [1,2]-Wittig rearrangement in aryl benzyl ethers.

\section{Results and Discussion}

$\alpha$-Lithiation of aryl benzyl ethers $1 . \quad[1,2]-$ Wittig rearrangement of aryl $\alpha$-lithiobenzyl ethers 2: Our previous report allowed us to establish the reaction conditions for the selective $\alpha$-lithiation of benzyl phenyl ether $\mathbf{1 a}$ as well as for the subsequent Wittig rearrangement of the intermediate organolithium 2a. ${ }^{[15]}$ To get a further insight into the mechanistic aspects of this reaction we prepared a wide selection of aryl benzyl ethers 1a-n, ${ }^{[16]}$ and carried out a detailed study concerning their lithiation conditions and the stability of the corresponding intermediate aryl $\alpha$-lithiobenzyl ether $\mathbf{2}$ with respect to the temperature (Table 1). Regarding the model substrate 1a, when treated with a slight excess of $t$-BuLi in THF at $-78{ }^{\circ} \mathrm{C}$ only the deuterated ether $3 \mathrm{a}$ was obtained after quenching with $\mathrm{MeOD}$, while at room temperature a complete conversion to diphenyl methanol $\mathbf{4 a}$, product derived from the expected [1,2]-Wittig rearrangement, took place. We also studied the stability towards reaction temperature of intermediate organolithium $\mathbf{2 a}$, finding that the [1,2]-Wittig rearrangement initiates at ca. $-30{ }^{\circ} \mathrm{C}$ (Table 1 , entry 1). Benzyl ethers $\mathbf{1 b}, \mathbf{c}$, bearing alkyl substituents at the para-position of the aryl moiety also underwent selective benzylic deprotonation at $-78{ }^{\circ} \mathrm{C}$, and the corresponding deuterated ethers $\mathbf{3 b}, \mathbf{c}$ were obtained after treatment with MeOD (entries 2 and 3 ). In the same way, starting ethers $\mathbf{1} \mathbf{d}-\mathbf{h}, \mathbf{l}, \mathbf{n}$ bearing an $o-, m$ - or $p$-MeO group, $p-\mathrm{Me}_{2} \mathrm{~N}, p-\mathrm{Cl}, m$-Ph, or 2-naphthyl groups were also tried giving rise to the corresponding $\alpha$-deuterated ethers $\mathbf{3 d}-\mathbf{h}, \mathbf{I}, \mathbf{n}$ at the same temperature (entries 4-8, 12 and 14). Only with ethers $1 \mathbf{j}, \mathbf{k}$, possessing a $\mathrm{o}-\mathrm{Cl}$ or $p$ - $\mathrm{Ph}$ group, a slight increase in the reaction temperature was required to reach complete $\alpha$-lithiation (entries 10 and 11). In the specific case of benzyl 3-chlorophenyl ether $\mathbf{1 i}$, it was impossible to achieve selective $\alpha$-lithiation likely due to competitive $o$-lithiation leading to aryne generation and further decomposition (entry 9). Surprisingly, a significant increase in the reaction temperature was necessary to effectively lithiate benzyl 1-naphtyl ether $\mathbf{1 m}$ at a-position. Whereas no reaction took place at $-78^{\circ} \mathrm{C}$, from ca. $-50^{\circ} \mathrm{C}$ the $\alpha$-lithiation reaction started, immediately followed by the $[1,2]-$ Wittig rearrangement of the corresponding organolithium $2 \mathrm{~m}$, which prevented the isolation of the deuterated ether $\mathbf{3 m}$ (entry 13). Not evidently, methoxy-functionalized ethers $\mathbf{1 d}, \mathbf{f}, \mathbf{g}$ were efficient and selectively lithiated at the $\alpha$-position without significant competition for lithiation at the aryl ring. This fact is especially significant for benzyl 3-methoxyphenyl ether $\mathbf{1 f}$, which possesses an aromatic proton flanked by two alkoxy groups (entry 6). It is also important to remark that all the deuterated ethers 3 , except $\mathbf{3 m}$, were isolated in very high yields and with almost complete deuteration at the $\alpha$-position.

Next, to evaluate the influence of different substituents on the stability of $\alpha$-lithiated species 2 towards the [1,2]-Wittig rearrangement we carried out lithiation reactions at the temperature that model substrate $1 \mathbf{a}$ starts to rearrange $\left(-30^{\circ} \mathrm{C}\right)$ and at room temperature, when $1 \mathbf{a}$ has completely undergone the Wittig rearrangement. So, organolithiums $\mathbf{2 b , c}$ bearing a methyl or $t$-butyl group at para-position are stable enough at $-30{ }^{\circ} \mathrm{C}$ to give rise exclusively to the corresponding deuterated ethers $\mathbf{3 b}, \mathbf{c}$ after quenching with $\mathrm{MeOD}$, whereas at room temperature only moderate yields of the corresponding rearranged alcohols $\mathbf{4 b , \mathbf { c }}$ were obtained showing that the rearrangement is clearly slower than in the case of $1 a^{[17]}$ In addition, trace amounts of cyclopropane derivative $\mathbf{5}$, derived 
from an a-elimination process of intermediate organolithium 2, were obtained for $\mathbf{1 b}$ (entries 2 and 3 ). Notably, a-lithiobenzyl ethers 2d,e bearing $p$-methoxyphenyl and $p$ dimethylaminophenyl groups are reluctant to suffer the rearrangement even at room temperature being stable enough to allow their deuteration and subsequent isolation of ethers $\mathbf{3 d}$ and $3 e$ (entries 4 and 5). The same tendency is observed with starting ether 1f, bearing a $m$-MeO group, as deuterated ether $\mathbf{3 f}$ is the only product at $-30{ }^{\circ} \mathrm{C}$, although partial deuteration at the ortho-position was observed probably due to an anion translocation process. In this sense, only a small amount of the corresponding alcohol $\mathbf{4 f}$ could be obtained at room temperature with ether $\mathbf{3} f$ being the major compound mostly deuterated at the ortho-position (entry 6). Unexpectedly, considering the result of $p$-methoxy-functionalized ether $\mathbf{1 d}$, o-methoxy-functionalized ether 19 shows a similar behavior than the observed with the parent ether 1a leading selectively to the rearranged alcohol $\mathbf{4 g}$ at RT (entry 7). On the other hand, aryl a-lithiumbenzyl ethers 2 bearing EWG such as chloro or phenyl undergo the [1,2]-Wittig rearrangement at lower temperature than the model substrate 1a, being the alcohol the only or the major product at room temperature (entries 8, 10-12). In addition, the fact that $\alpha$ deuteriobenzyl 1-naphthyl ether $\mathbf{3 m}$ was never obtained means that the corresponding organolithium $\mathbf{2 m}$ is really prone to suffer the [1,2]-Wittig rearrangement even at low temperature (entry 13). A similar behavior towards the rearrangement can be observed in the case of benzyl 2-naphthyl ether 1n, the rearranged alcohol $4 \mathrm{n}$ being the only product at $-30^{\circ} \mathrm{C}$, as well as at RT (entry 14).

Table 1. $\alpha$-Lithiation and further evolution of aryl benzyl ethers $\mathbf{1}$.

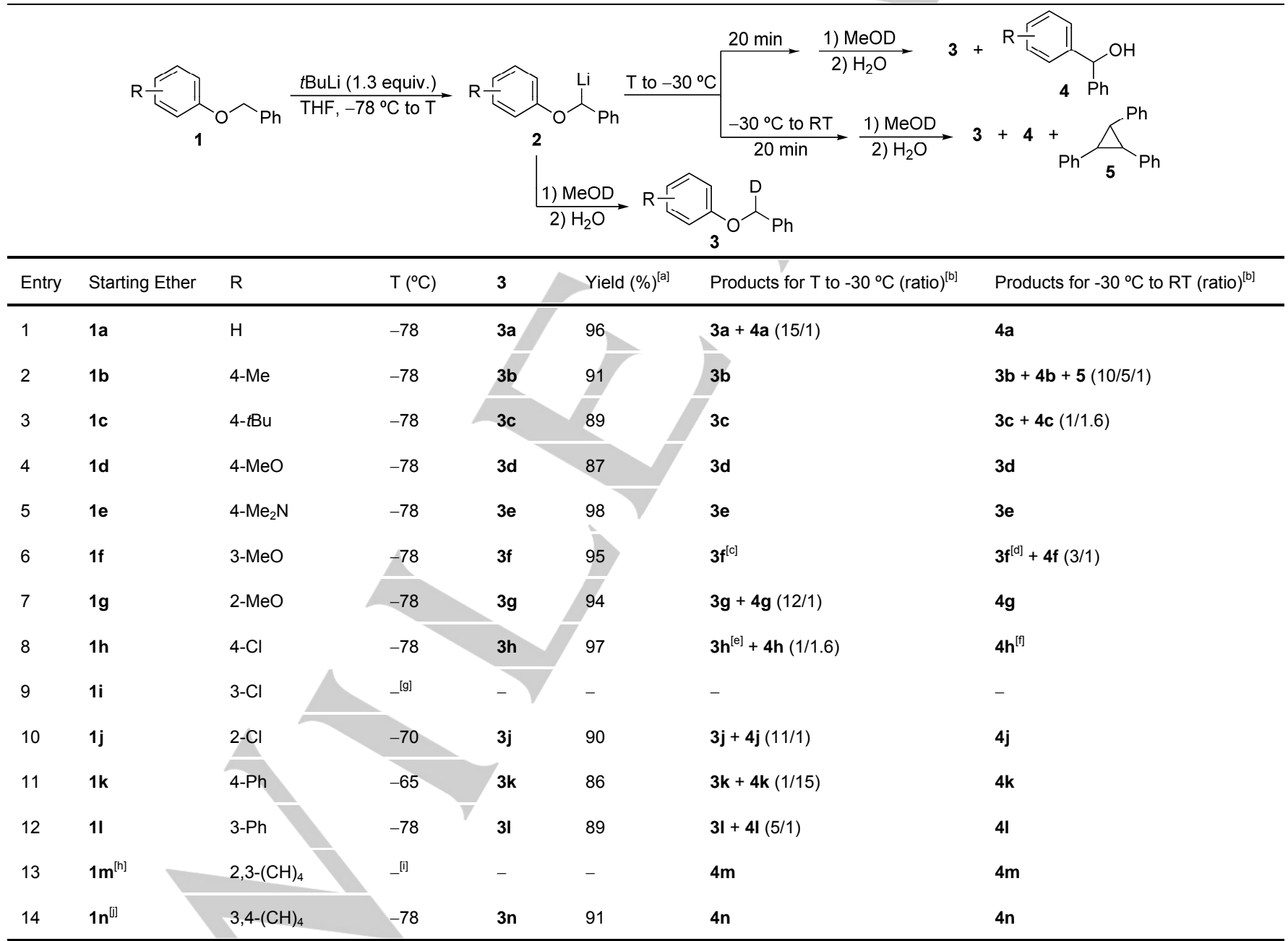

[a] Isolated yield. [b] Isolated yield of the mixtures are typically higher than $85 \%$. [c] Partially deuterated at the ortho and para positions of the methoxypheny ring. [d] $3 \mathrm{f}$ is benzyl 2-deuterio-3-methoxyphenyl ether ( $80 \% \mathrm{D})$. [e] $\sim 80 \%$ deuterium incorporation. [f] $\sim 15 \%$ of starting ether $1 \mathrm{~h}$ was also isolated. [g] $3 \mathbf{i}$ and/or 4i were not obtained likely due to competitive elimination processes. [h] Benzyl 1-naphthyl ether. [i] At $-78^{\circ} \mathrm{C}$ no metalation takes place. At $-50{ }^{\circ} \mathrm{C}$ a mixture of non-lithiated $1 \mathrm{~m}$ and rearranged alcohol $4 \mathrm{~m}$ is obtained. At $-30^{\circ} \mathrm{C} 4 \mathrm{~m}$ is generated along with trace amounts of $1 \mathrm{~m}$. [j] Benzyl 2-naphthyl ether. 
Finally, we also checked that, as previously reported, ${ }^{[8 a]} 6 \mathrm{H}$ benzo[c]chromene 10 also undergoes Wittig rearrangement leading to 9-fluorenol 4o, although an excess of base was required for complete conversion. The behavior of 10 is similar to benzyl 1-naphthyl ether $1 \mathrm{~m}$ as the corresponding deuterated ethers 3 were never obtained and the rearrangement is complete even at $-30^{\circ} \mathrm{C}$ (Scheme 3 ).

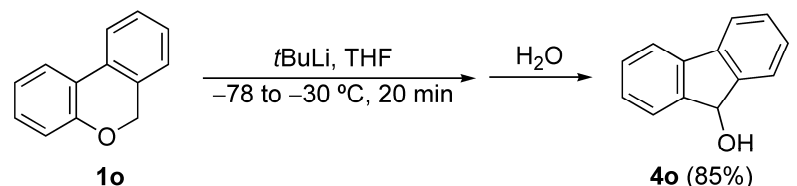

Scheme 3. Wittig rearrangement of $6 \mathrm{H}$-benzo[c]chromene 10.

Theoretical studies: Some of the obtained results seem to be contradictory if we consider the existence of only one of the proposed mechanisms (Scheme 2). For instance, the unexpected reluctance of $p$-methoxy or $p$-dimethylaminophenyl ethers 1 d,e to undergo Wittig rearrangement could lead us to think that the anionic pathway is operating. However, the different behavior of the regioisomeric o-methoxyphenyl ether $\mathbf{1 g}$ is in disagreement with this assumption. In the same way, the fact that $6 \mathrm{H}$-benzo[c]chromene $\mathbf{1 0}$ also undergoes Wittig rearrangement also seems to be against the anionic proposal that would involve the formation of a highly strained bridged intermediate. Moreover, the higher tendency of 4-biphenyl ether $\mathbf{1 k}$, as well as naphthyl ethers $\mathbf{1 m}$ and $\mathbf{1 n}$, could not be easily explained through the radical pathway. To shed more light on the mechanism of the Wittig rearrangement in aryl benzyl ethers and in order to understand the results obtained for the different substrates in Table 1, we decided to use DFT to model two different paths, one of radical nature and other of anionic character (see Figure 1).

Computational methods: We have used DFT to locate the stationary points depicted in the first two reaction paths in Figure 1. We have carried out geometry optimizations with the B3LYP hybrid exchange-correlation functional with the double- $\zeta 6-31 \mathrm{G}^{*}$ basis set, as implemented in the Gausian09 code. ${ }^{[18]}$ We have confirmed that the wavefunctions are stable and used harmonic analysis to characterize these structures as either minima or transition states in the potential energy surface. These harmonic frequencies have been used to calculate the thermal corrections needed to obtain free energies. In some cases we have run IRC calculations to unambiguously connect transition states and the corresponding minima. For obtaining more accurate electronic energies, we have used the double hybrid B2PLYP functional with Grimme's dispersion correction (B2PLYP-D3) ${ }^{[19]}$ with the triple- $\zeta$ basis def2-tzvpp, ${ }^{[20]}$ which includes extra polarization functions, on the previously optimized geometries. The Orca program $^{[21]}$ has been used for this. All the calculations have been carried out in THF solution, using either $\mathrm{PCM}^{[22]}$ (low level geometry optimizations) or $\mathrm{COSMO}^{[23]}$ (energy refinements).

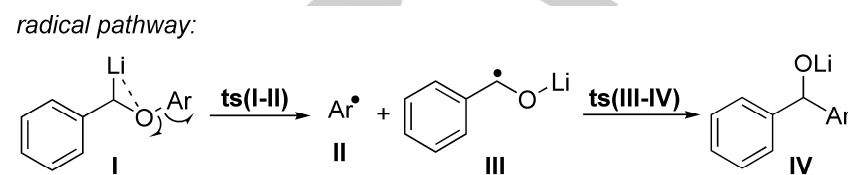

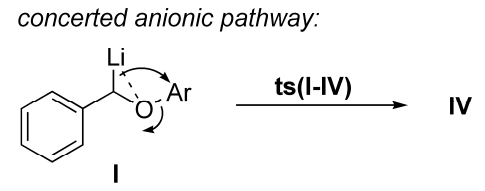

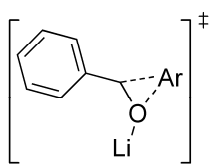

ts(I-IV)

stepwise anionic pathway<smiles>CC1(C)OC1(c1ccccc1)c1ccccc1</smiles>

Figure 1. Mechanisms for the Wittig rearrangement considered in the DFT study.

Computational results: The radical pathway would involve the homolitic cleavage of the ether $\mathrm{Ar}-\mathrm{O}$ bond in I, leading to the aryl radical II and benzyloxy radical III. Recombination of these two radicals through a barrierless transition state ts(III-IV) provides the reorganized product IV. An alternative anionic path would involve an attack of the benzylic anion to the aryl group that would be concerted with the cleavage of the $\mathrm{Ar}-\mathrm{O}$ bond, directly leading to the reorganized product IV. Also with anionic character, we proposed a third option where the attack of the anion to the aryl group would lead to an oxirane intermediate $\mathbf{V}$ that would then undergo ring-opening to produce IV, but we were not able to locate such an intermediate, at least for $\mathrm{Ar}=$ $\mathrm{Ph}$.

In Table 2, we show the relative Gibbs free energies of the different structures found along these two paths for some representative ethers from Table 1. We found that there is not a generally preferred mechanism, and that in some instances, the radical and anionic concerted paths can be considered to be competitive and can coexist. If we compare the activation energies for ts(I-II) (the later collapse of the two radicals is found to be a barrierless process) and ts(III-IV), we find that the concerted path is favored when $\mathrm{Ar}=\mathrm{Ph}(\mathbf{1 a}), 4-\mathrm{CIC}_{6} \mathrm{H}_{4}(\mathbf{1 h}), 1$ naphthyl (1m), 2-naphthyl (1n), and 6H-benzo[c]chromene (10) (entries 1 and 6-9, highlighted in blue), and slightly preferred when $\mathrm{Ar}=4-\mathrm{MeC}_{6} \mathrm{H}_{4}$ (1) (entry 2). In contrast, ts(I-II) is preferred with electron richer aryl groups, such as $\mathrm{Ar}=4-$ $\mathrm{MeOC}_{6} \mathrm{H}_{4}(\mathbf{1 d}), 4-\mathrm{Me}_{2} \mathrm{NC}_{6} \mathrm{H}_{4}(\mathbf{1 e})$ and 2- $\mathrm{MeOC}_{6} \mathrm{H}_{4}(\mathbf{1 g})$ (entries 
3-5). In these cases (highlighted in red), however (as happened with $\mathrm{Ar}=4-\mathrm{MeC}_{6} \mathrm{H}_{4}(\mathbf{1 b})$ (entry 2)) both paths are competitive, with differences between the two rate determining steps of less than $1.0 \mathrm{kcal} \mathrm{mol}^{-1}$.

The preference for a radical or anionic concerted mechanism seems to be electronic in nature, since we found that one of the largest differences between the activation energy of the two alternative paths is found in $6 \mathrm{H}$-benzo[c]chromene (1r), where the preferred anionic concerted mechanism could be expected to be prevented by the rigidity of the structure. The observed trends in reactivity are well replicated in our calculations: $6 \mathrm{H}$ benzo[c]chromene (1r), naphthyl ethers $\mathbf{1 m}, \mathbf{n}$ and 4chlorophenyl ether $\mathbf{1 h}$ rearrange faster than the parent phenyl ether 1a and 4-methoxyphenyl or 4-aminomethyl ethers $\mathbf{1 d , e}$ do not rearrange at all. The fact that we don't find rearrangement product for 4-methoxyphenyl ether 1d whereas 2-methoxyphenyl ether $\mathbf{1 g}$ rearranges readily, is puzzling from a purely electronic point of view, since the difference in activation of the phenyl ring shouldn't be very large between the two systems. What is found here is that the geometry of the substrate is key in determining the reactivity. The barriers for ts(I-II) and ts(I-IV) are comparable for $\mathrm{Ar}=4$-methoxyphenyl $\left(26.9\right.$ and $27.8 \mathrm{kcal} \mathrm{mol}^{-1}$, respectively) (entry 3 ) and for $\mathrm{Ar}=2$-methoxyphenyl (28.2 and $26.9 \mathrm{kcal} \mathrm{mol}^{-1}$ ) (entry 5), provided that the lithium cation is not allowed to interact with the methoxy substituent. If the methoxy group is located so that it can coordinate with lithium, the two barriers are significantly lowered $\left(18.9 \mathrm{kcal} \mathrm{mol}^{-1}\right.$ for ts(I-II) and $19.4 \mathrm{kcal} \mathrm{mol}^{-1}$ for ts(I-IV)), making this reaction much more favorable than the rearrangement of the 4-methoxyphenyl system.

As a general trend, we found that electron-rich aryl groups (Ar) lower the barrier of the usually more energetic radical path (ts(III)), as expected from the electron-deficient nature of the radical intermediate II, whereas electron-poor aryls correspondingly raise it. The effect of the aryl's charge, however, is opposite, and more pronounced, in the anionic concerted mechanism; with electron-poor aryls clearly favoring this path. The structure of ts(I-IV), where the attacking carbanion can overlap with the $\pi$ system of the aromatic ring, fully supports this observation.

An extreme case of this electronic effect on the preference for one path or the other and on the reaction barrier is found when a very good electron-acceptor aryl group $\left(\mathrm{Ar}=4-\mathrm{NO}_{2} \mathrm{C}_{6} \mathrm{H}_{4}\right)$ is used (entry 10). This substrate has not been tested experimentally, but computational data predict for it the lowest barrier in the studied set $\left(14.1 \mathrm{kcal} \mathrm{mol}^{-1}\right)$ and a very strong preference for the anionic path. Conversely, a very strong electron-donor aryl group (Ar $=2,4,6-\left(\mathrm{Me}_{2} \mathrm{~N}\right)_{3} \mathrm{C}_{6} \mathrm{H}_{2}$, entry 11$)$ is able to induce a mechanism switch so that the radical path is clearly (with a difference in activation barriers of $4.9 \mathrm{kcal} \mathrm{mol}^{-1}$ ) preferred now, thus validating our model.

Table 2. B2PLYP/def2-tzvpp(COSMO,THF)//B3LYP/6-31G*(PCM,THF) Gibbs free energies $\left(\mathrm{kcal} \mathrm{mol}^{-1}\right)$ relative to I for the structures depicted in Figure 1. ${ }^{\text {[a] }}$ Structures strongly favoring the concerted mechanism have been highlighted in blue, those favoring the radical mechanism in red, and those where the two mechanisms are expected to be competitive, in orange.

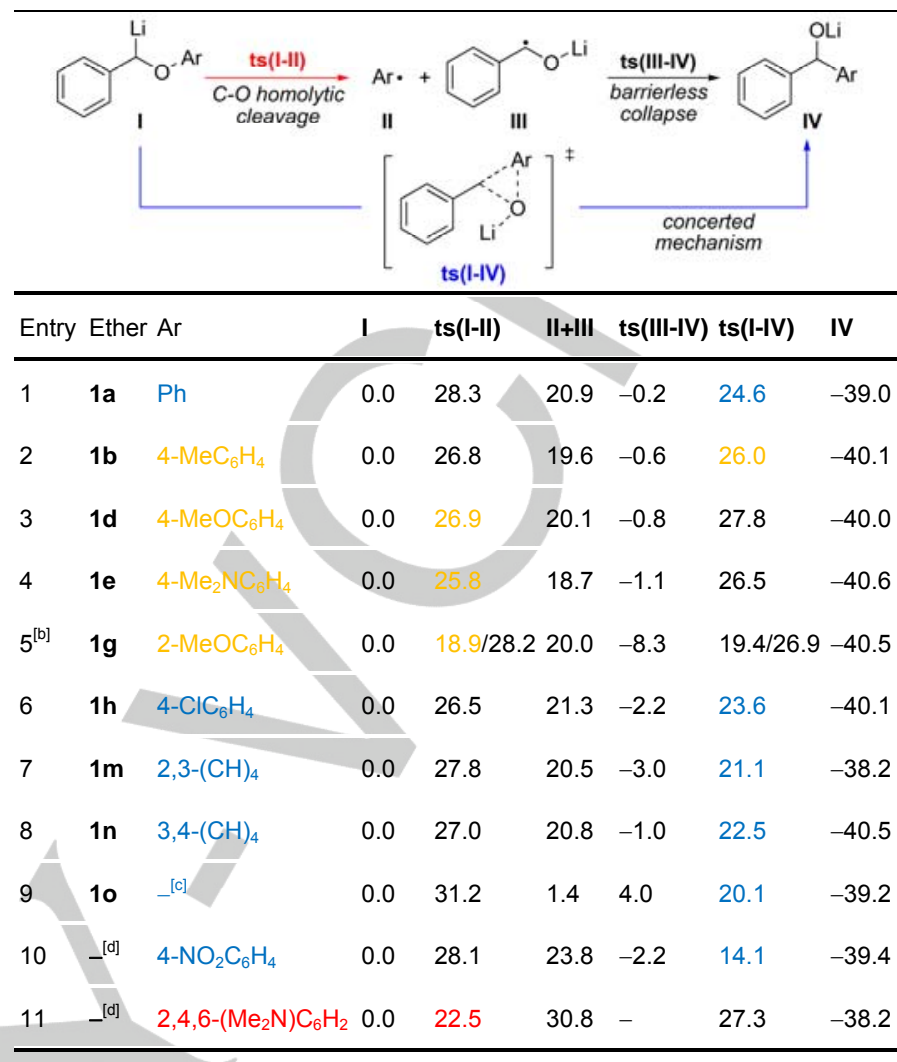

[a] They also correspond to activation free energies in the case of ts(I-II) and ts(I-IV). [b] The two values for ts(I-II) and ts(I-IV) correspond to the structures with (the lowest values) and without the directing effect of the methoxy group. [c] 6H-benzo[c]chromene (10). [d] Benzyl 4-nitrophenyl ether and 2,4,6tris(dimethylamino)phenyl ether were not checked experimentally.
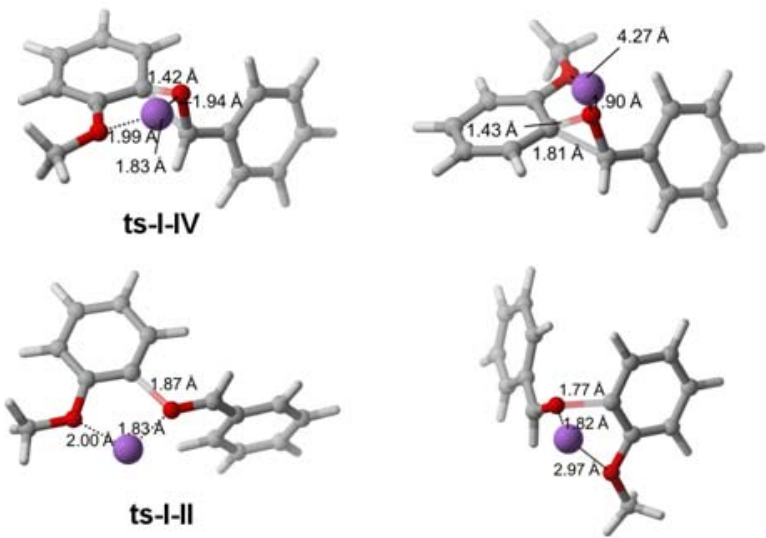

Figure 2. Structures of the two alternate structures for ts(I-IV) and ts(I-II) when $\mathrm{Ar}=2-\mathrm{MeOC}_{6} \mathrm{H}_{4}$. The first structure is considerably lower in energy than the second, thanks to the extra coordination of the oxygen in the methoxy substituent with the lithium cation. 
Functionalization of $\alpha$-lithiobenzyl ethers 2: With a general protocol in place to obtain the corresponding $\alpha$-lithiated ethers 2 from easily available aryl benzyl ethers $\mathbf{1}$, we next surveyed their reactivity towards representative electrophiles to demonstrate the applicability of this approach for accessing a library of functionalized aryl benzyl ethers 6 (Table 3). Several electrophilic reagents were reacted with benzyl phenyl ether 1a under the optimized conditions. Addition of alkyl halides gave high yields of the corresponding $\alpha$-alkylated ethers $\mathbf{6 a a}$ and $\mathbf{6 a b}$ (entries 1 and 2). Likewise, the use of $\mathrm{TMSCl}$ or $\mathrm{Bu}_{3} \mathrm{SnCl}$ resulted in the direct formation of functionalized ethers 6ac and 6ad (entries 3 and 4). Different carbonyl compounds are also useful electrophilic partners for the intermediate organolithiums 2. Their reactions with aliphatic and aromatic ketones and aldehydes also proceeded efficiently, leading to the expected alcohols 6ae-am in good yields (entries 5-13). The reaction was also amenable to an imine or an epoxide as electrophiles, giving rise to products 6an and 6ao respectively (entries 14 and 15). Unfortunately, when we tested an aromatic nitrile as electrophile, the reaction yielded the expected ketone 6ap in low yield after acid workup (entry 16). We have also investigated the metalation and subsequent functionalization of other aryl benzyl ethers (entries 17-23), showing exactly the same behavior as the parent ether 1a. In all cases, when two stereogenic centers are generated, the final compound is obtained as a variable mixture of diastereoisomers.

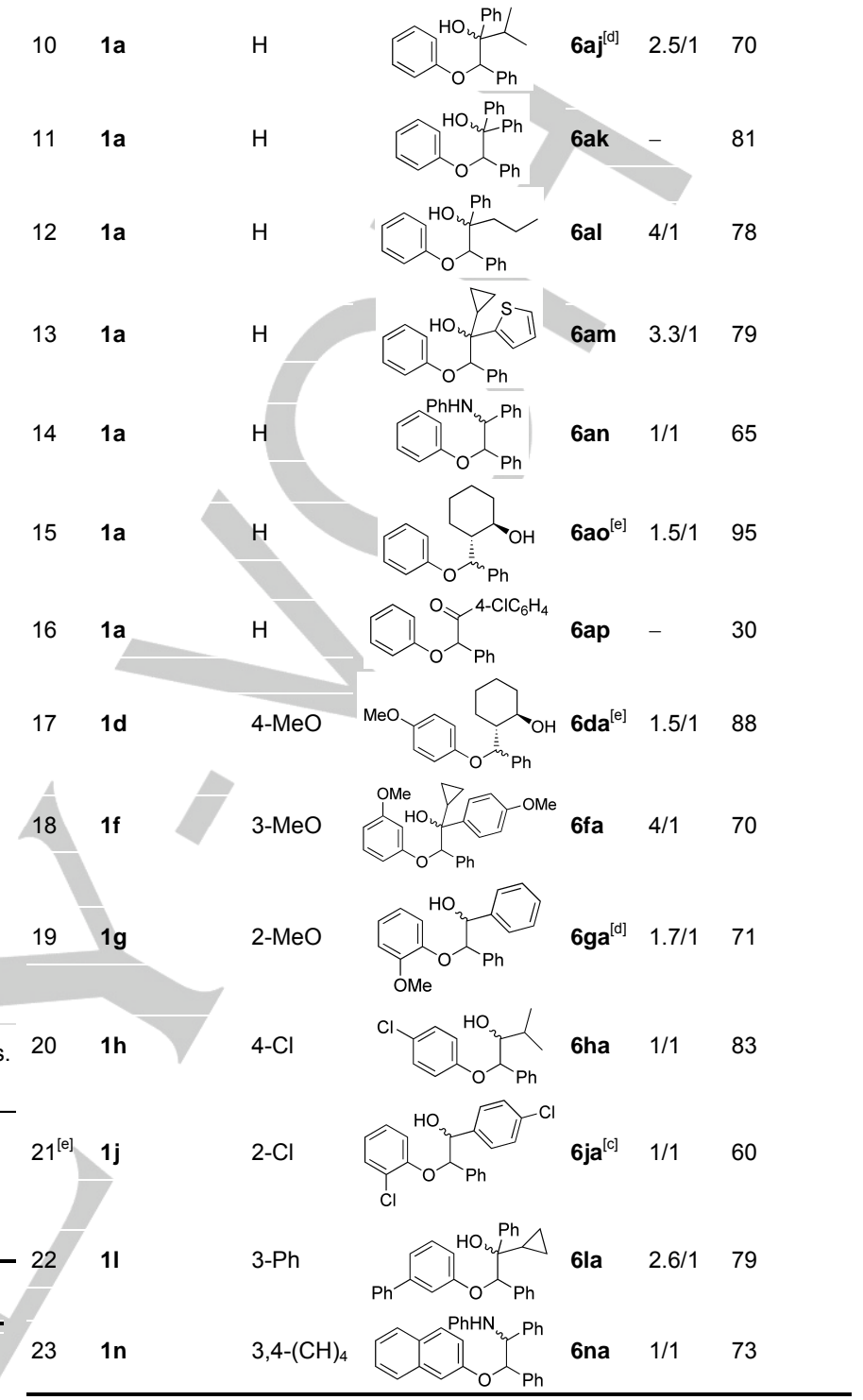

[a] Ratio of diastereoisomers determined by ${ }^{1} \mathrm{H}$ NMR analysis of the crude reaction mixture. [b] Isolated yield referred to the starting ether 1. [c] Both diastereoisomers could be independently isolated. [d] The major diastereoisomer could be isolated in pure form. [e] Lithiation carried out from -78 to $-70^{\circ} \mathrm{C}$

Transition metal-free homocoupling of $\alpha$-lithiobenzyl ethers 2: The oxidative coupling of two nucleophilic carbon atoms is a powerful methodology for constructing $\mathrm{C}-\mathrm{C}$ bonds, which is typically catalyzed by transition metal complexes. ${ }^{[2]}$ Few examples of transition metal-free protocols employing organic oxidants for the oxidative coupling of Grignard reagents or other organometallic compounds have been reported. ${ }^{[25]}$ In this field, the oxidative coupling of benzyl anions, derived from toluene derivatives, with 1,2-dibromoethane has been described by O'Shea and co-workers. ${ }^{[26]}$ We decided to tackle the homooxidative coupling of $\alpha$-lithiobenzyl phenyl ether 2a using different halogen-based reagents. As shown in Scheme 4, a 
variety of organic halides were tested and in all cases the diether $7 \mathrm{a}$ was formed. This study revealed that the best yield was obtained when one equivalent of hexachloroethane was used. This inexpensive reagent was tested as oxidant with a selection of benzyl phenyl ethers 1 giving rise to the corresponding dimers $\mathbf{7 d}, \mathbf{h}, \mathbf{k}$ in good to excellent yields, which were obtained as a ca. 1:1 mixture of diastereoisomers. Interestingly, compounds $\mathbf{7}$ are diaryl protected 1,2diphenylethanediols, which are generated in a straightforward manner from aryl benzyl ethers. Only $7 a$ has been previously prepared in very low yield by radical dimerization of benzyl phenyl ether in the presence of $t$-butyl peroxide ${ }^{[27]}$ or by photolysis of benzoin phenyl ether. ${ }^{[28]}$ Regarding the mechanism two alternative pathways could be proposed for the formation of the coupled products 7 . One of them would involve an initial halogenation of the corresponding organolithium 2 and the subsequent trapping of the new halogenated intermediate with the remaining unreacted 2 (path a). Alternatively, a one electron oxidation of $\mathbf{2}$ with further dimerization of the corresponding radical would also account for the obtained results (path $b$ ). The generation of $\mathbf{7}$ as an almost equimolecular mixture of meso and dl dimers in all cases supports the radical pathway, as it is known that steric and polar factors are not important in the dimerization of $\mathrm{PhC}$ CHOPh radical, which leads to equal amounts of both dimers. ${ }^{[29]}$ It is also remarkable that as the generation of the two nucleophiles is achieved through $\mathrm{C}-\mathrm{H}$ deprotonation, this strategy allows the direct access to functionalized 1,2diarylethanes from simple coupling partners without any preactivation or the use of a transition metal catalyst.

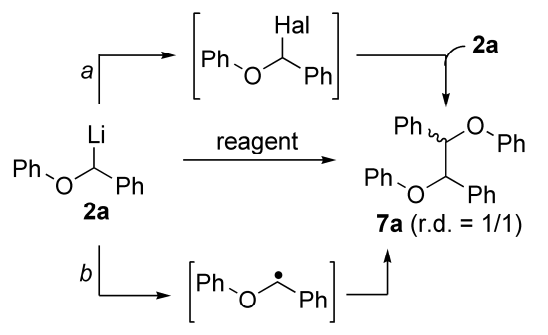

\begin{tabular}{cc} 
reagent & yield (\%) ${ }^{[\mathrm{a}]}$ \\
\hline $\mathrm{Phl}$ & 46 \\
$\mathrm{PhBr}$ & 10 \\
$\mathrm{CH}_{2} \mathrm{I}_{2}$ & 52 \\
$\mathrm{I}_{2}$ & 62 \\
$\left(\mathrm{CH}_{2}\right)_{2} \mathrm{Br}_{2}$ & 84 \\
$\mathrm{CBr}_{4}$ & 57 \\
2- $\mathrm{MeOC}_{6} \mathrm{H}_{4} \mathrm{Br}$ & 78 \\
$\mathrm{C}_{2} \mathrm{Cl}_{6}$ & 90 \\
\hline [a] Determined by ${ }^{1} \mathrm{H}$ NMR \\
using internal standard.
\end{tabular}
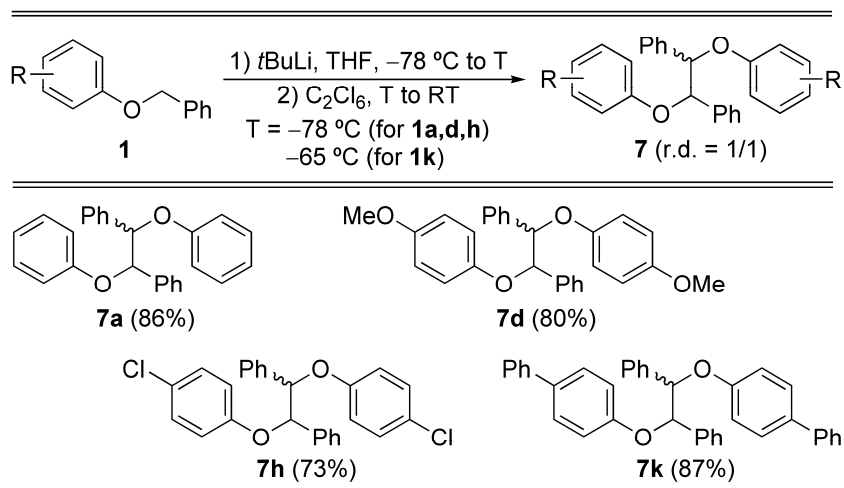

Scheme 4. Dimerization of organolithiums 2. Synthesis of diaryl protected glycols 7.
Reactions of $\alpha$-lithiobenzyl ethers 2 with carboxylic esters: Surprisingly, when ethyl benzoate was used as the electrophilic quenching of $\mathbf{2 a}$, the aromatic ketone $\mathbf{8 a a}$ was exclusively obtained rather than the expected tertiary alcohol, irrespective of the amount of ester added (Scheme 5 and Table 4). In this way, a wide variety of ketones $\mathbf{8}$ were synthesized in good yields using a selection of carboxylic esters derived from (hetero)aromatic acids (Table 4). To account for this unexpected result, we propose that the initially formed ketone $\mathbf{8}$ undergoes deprotonation by lithium ethoxide, generated in the first step, leading to the corresponding enolate $\mathbf{9}$, which remains intact prior to hydrolysis. Our proposal was supported by the fact that, upon addition of methyl iodide, prior to aqueous workup, ketone 10 bearing an $\alpha$-quaternary center was obtained (Scheme 5 ). It is also remarkable that by employing carboxylic esters as electrophiles, ketones $\mathbf{8}$ are obtained in significantly higher yields than when using aromatic nitriles as electrophiles (see Table 3, entry 16).

$$
\begin{aligned}
& \text { 1a }(\mathrm{R}=\mathrm{H}) \frac{t \mathrm{BuLi}, \mathrm{THF}}{-78^{\circ} \mathrm{C}} \frac{\text { 1) } \mathrm{PhCO}_{2} \mathrm{Et},-78^{\circ} \mathrm{C} \text { to } \mathrm{RT}}{\text { 2) } \mathrm{Mel}, \mathrm{RT}} \\
& \text { 2) } \mathrm{ArCO}_{2} \mathrm{Et},-78^{\circ} \mathrm{C} \text { ro RT }
\end{aligned}
$$

\begin{tabular}{|c|c|c|c|c|c|}
\hline & $\gamma_{\mathrm{Ph}}$ & & $\begin{array}{l}\text {-i (1.3 equ } \\
\mathrm{F},-78^{\circ} \mathrm{C} \\
\text { Et, }-78^{\circ} \mathrm{C} \\
\text { 3) } \mathrm{H}_{2} \mathrm{O}\end{array}$ & 4 & $Y^{A r}$ \\
\hline Entry & Starting Ether & $\mathrm{R}$ & Product & $\mathrm{Ar}$ & Yield $(\%)^{[a]}$ \\
\hline 1 & $1 \mathrm{a}$ & $\mathrm{H}$ & $8 \mathbf{a a}$ & $\mathrm{Ph}$ & 73 \\
\hline 2 & $1 a$ & $\mathrm{H}$ & $8 a b$ & 2-Th & 60 \\
\hline 3 & $1 a$ & $\mathrm{H}$ & $8 a c$ & $2-\mathrm{ClC}_{6} \mathrm{H}_{4}$ & 72 \\
\hline 4 & $1 a$ & $\mathrm{H}$ & $8 \mathbf{a d}^{[b]}$ & 4- $\mathrm{ClC}_{6} \mathrm{H}_{4}$ & 76 \\
\hline 5 & $1 a$ & $\mathrm{H}$ & $8 a e$ & 4- $\mathrm{MeOC}_{6} \mathrm{H}_{4}$ & 83 \\
\hline 6 & $1 b$ & 4-Me & $8 \mathrm{be}$ & 4- $\mathrm{MeOC}_{6} \mathrm{H}_{4}$ & 74 \\
\hline 7 & $1 \mathrm{~h}$ & $4-\mathrm{Cl}$ & 8 ha & $\mathrm{Ph}$ & 70 \\
\hline
\end{tabular}

Scheme 5. Reaction of aryl $\alpha$-lithiobenzyl ethers 2 with carboxylic esters: Synthesis of ketones $\mathbf{8}$ and $\mathbf{1 0}$.

Table 4. Carboxylic esters as electrophiles. Synthesis of ketones 8 


\begin{tabular}{llllll}
8 & 1) & 3-Ph & 8lb & 2-Th & 65 \\
9 & 1n & $3,4-(\mathrm{CH})_{4}$ & 8na & $\mathrm{Ph}$ & 66 \\
\hline
\end{tabular}

[a] Isolated yield referred to the starting ether 1. [b] This ketone is the same as obtained when using 4-chlorobenzonitrile as electrophile (see product 6ap Table 3, entry 16).

Furthermore, taking advantage of the initial formation of these ketones 8 we decided to make an attempt on the diastereoselective synthesis of alcohols $\mathbf{6 a f}, \mathbf{6 a g}$ and $\mathbf{6 a h}$, previously synthesized with different diastereoisomeric ratios by reaction of $\alpha$-lithiobenzyl phenyl ether $\mathbf{2 a}$ with (hetero)aromatic carboxaldehydes. Interestingly, it was possible to selectively obtain either one diastereoisomer or the other of the corresponding alcohol 6 by treating selected $\alpha$-phenoxy ketones 8aa, 8ab, and 8ae with Red-Al or $\mathrm{Al}(\mathrm{O} i-\mathrm{Pr})_{3} / i-\mathrm{PrOH}$ (Scheme 6). So, Red-Al gave rise to the corresponding monoprotected 1,2anti-diols anti-6 in good to excellent yields and high diastereoselection through a 1,2-chelation-controlled reduction. ${ }^{[30]}$ On the other hand, high syn selectivity was obtained via Felkin-Ahn control using a Meerwein-PonndorfVerley reduction allowing the preparation of protected 1,2-syndiols syn-6. ${ }^{[31]}$ Remarkably, besides diastereoselectively accessing to diol derivatives $\mathbf{6}$, this study allowed us to establish that reactions of organolithium $\mathbf{2 a}$ with (hetero)aromatic aldehydes always take place with moderate syn selectivity (see Table 3, entries 6-8).

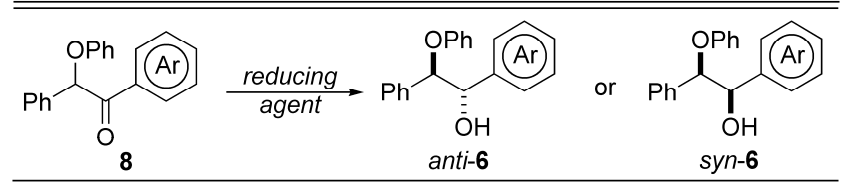

\begin{tabular}{cccccc}
\hline \hline Ketone & $\mathrm{Ar}$ & Reagent & antilsyn & Product & Yield (\%) \\
\hline 8ab & 2-Th & Red-Al & $4 / 1$ & anti-6af & 93 \\
8ab & 2-Th & $\mathrm{Al}(\mathrm{O} i-\mathrm{Pr})_{3} / i-\mathrm{PrOH}$ & $1 / 17$ & syn-6af & 89 \\
8ae & $4-\mathrm{MeOC}_{6} \mathrm{H}_{4}$ & Red-Al & $>20 / 1$ & anti-6ag & 96 \\
8ae & $4-\mathrm{MeOC}_{6} \mathrm{H}_{4}$ & $\mathrm{Al}(\mathrm{O} i-\mathrm{Pr})_{3} / i-\mathrm{PrOH}$ & $<1 / 20$ & syn-6ag & 91 \\
8aa & $\mathrm{Ph}$ & $\mathrm{Red}-\mathrm{Al}$ & $>20 / 1$ & anti-6ah & 92 \\
8aa & $\mathrm{Ph}$ & $\mathrm{Al}(\mathrm{O} i-\mathrm{Pr})_{3} / i-\mathrm{PrOH}$ & $<1 / 20$ & syn-6ah & 90
\end{tabular}

Scheme 6. Diastereoselective access to alcohols 6af-h.

Lithiation of dimethoxyphenyl benzyl ethers 1p-r and reactions with carbonyl compounds: Considering the complete selectivity for the $\alpha$-lithiation of benzyl 3methoxyphenyl ether 1f, we decided to study the lithiation reaction of dimethoxyphenyl ethers 1p-r (Scheme 7). At low temperature $\left(-78^{\circ} \mathrm{C}\right.$ for $1 q$ and $1 \mathbf{r}$, or $-55^{\circ} \mathrm{C}$ for $\left.1 p\right)$, we found that $1 \mathbf{p}$ and $\mathbf{1 q}$ were selectively $\alpha$-lithiated with $t$ BuLi leading to the corresponding $\alpha$-deuterated ethers $3 p, q$ on quenching with MeOD. By contrast, 3,4-dimethoxyphenyl ether $1 \mathrm{r}$ was mainly lithiated at the aryl ring generating 2 ' $r$, with a higher degree of metalation as the reaction temperature increases (almost complete lithiation at $-30^{\circ} \mathrm{C}$ ). It should be pointed out that related 3-methoxyphenyl ether 1f and 3.5-dimethoxyphenyl ether $\mathbf{1 q}$ were exclusively $\alpha$-lithiated at $-78^{\circ} \mathrm{C}$. By raising the temperature to RT, 2,3-dimethoxyphenyl ether 1p efficiently underwent Wittig rearrangement affording exclusively benzhydrol derivative $4 p$ (Scheme 7). Nonetheless, under the same conditions 3,5-dimethoxyphenyl ether 1q evolves through partial anion translocation to the activated aryl ring and so, a mixture of rearranged alcohol $\mathbf{4 q}$ and benzyl ether $\mathbf{3 q}$, with deuterium incorporation at the trialkoxyphenyl ring, was obtained at RT (Scheme 7).

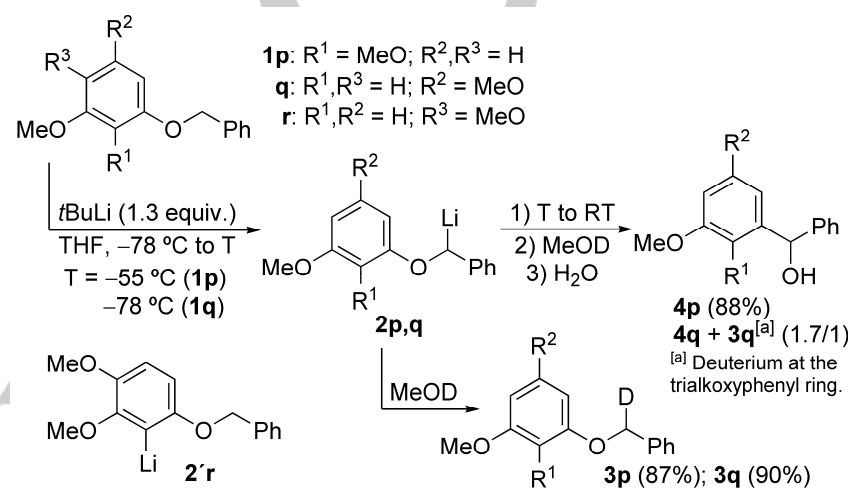

Scheme 7. Lithiation reactions of benzyl dimethoxyphenyl ethers 1p-r.

The above study showed that 2,3-dimethoxyphenyl and 3,5dimethoxyphenyl ethers, $\mathbf{1 p}$ and $\mathbf{1 q}$, could be selectively $\alpha$ lithiated at low temperature, without significant competition of alternative ortho-lithiation processes. We envisaged that the presence of these highly electron-rich aromatic rings could lead to intramolecular Friedel-Crafts reactions with properly functionalized ethers affording interesting oxygen heterocyclic scaffolds. To this end, we decided to evaluate the behavior of the $\alpha$-lithiated ethers $\mathbf{2 p , q}$ towards different (hetero)aromatic carbonyl compounds as electrophilic partners (Table 5). In this way, a variety of $\alpha$-aryloxy alcohol derivatives $\mathbf{1 1}$ were prepared in good yields and with low to moderate diastereoselectivity when aldehydes or non-symmetric ketones were used (entries 2 and 4-10). Again the major diastereoisomer obtained when (hetero)aromatic aldehydes were employed resulted to be the syn (entries 4-5 and 9-10), the same tendency observed for benzyl phenyl ether 1a (see Table 3, entries 6-8).

Table 5. $\alpha$-Lithiation of dimethoxyphenyl ethers $1 \mathbf{p , q}$ and reactions with carbonyl compounds. Synthesis of $\alpha$-aryloxy alcohols 11 .

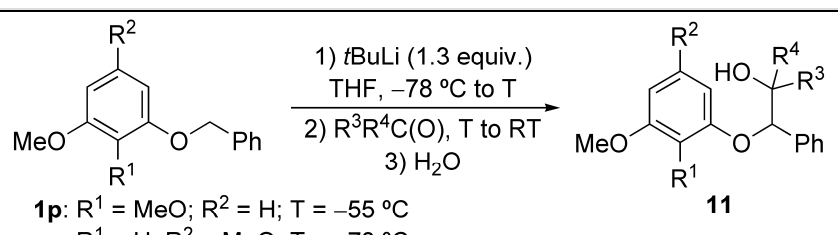

$\begin{aligned} & \text { 1p: } R^{1}=M e O ; R^{2}=H ; T=-55^{\circ} \mathrm{C} \\ & \text { q: } R^{1}=H ; R^{2}=M e O ; T=-78^{\circ} \mathrm{C}\end{aligned}$ 


\begin{tabular}{|c|c|c|c|c|c|c|c|}
\hline Entry & Ether & $\mathrm{R}^{1}$ & $\mathrm{R}^{2}$ & Product & & d.r..$^{[a]}$ & Yield $(\%)^{[b]}$ \\
\hline 1 & $1 p$ & $\mathrm{MeO}$ & $\mathrm{H}$ & & $11 a$ & - & 82 \\
\hline 2 & $1 p$ & $\mathrm{MeO}$ & $\mathrm{H}$ & & $11 b$ & $1: 1$ & 70 \\
\hline 3 & $1 p$ & $\mathrm{MeO}$ & $\mathrm{H}$ & & $11 \mathrm{c}$ & - & 74 \\
\hline 4 & $1 p$ & $\mathrm{MeO}$ & $\mathrm{H}$ & & 11d & $2.2: 1$ & 88 \\
\hline 5 & $1 p$ & $\mathrm{MeO}$ & $\mathrm{H}$ & & $11 \mathrm{e}$ & $1.6: 1$ & 73 \\
\hline 6 & $1 q$ & $\mathrm{H}$ & $\mathrm{MeO}$ & & $11 f$ & $1.5: 1$ & 83 \\
\hline 7 & $1 q$ & $\mathrm{H}$ & $\mathrm{MeO}$ & & $11 \mathrm{~g}$ & $3.5: 1$ & 80 \\
\hline 8 & $1 q$ & $\mathrm{H}$ & $\mathrm{MeO}$ & & $11 \mathrm{~h}$ & $2.5: 1$ & 74 \\
\hline 9 & $1 q$ & $\mathrm{H}$ & $\mathrm{MeO}$ & & $11 \mathrm{i}$ & $2: 1$ & 76 \\
\hline 10 & $1 q$ & $\mathrm{H}$ & $\mathrm{MeO}$ & & 11j & $3.5: 1$ & 72 \\
\hline
\end{tabular}

[a] Ratio of diastereoisomers determined by ${ }^{1} \mathrm{H}$ NMR analysis of the crude reaction mixture. [b] Isolated yield referred to the starting ether $1 \mathbf{p , q}$ dihydrobenzofuran derivatives $\mathbf{1 2 a}, \mathbf{c}, \mathbf{g}, \mathbf{h}$ in high yield (Scheme 8). ${ }^{[5]}$ However, this catalyst proved unsuccesful for substrates possesing secondary hydroxyl groups such as $\mathbf{1 1 d}$ and $\mathbf{1 1}$, which could be cyclized in low yield to the corresponding dihydrobenzofuran $\mathbf{1 2}$ as variable mixture of diastereoisomers employing $\mathrm{Hg}(\mathrm{OTf})_{2}$ as catalyst (Scheme 8$)^{[36]}$ Interestingly, benzofuran derivative $\mathbf{1 2 \mathrm { g }}$ was obtained as single diastereoisomer whose configuration was initially assigned to the trans isomer based on the comparison between the experimental and mPW1PW91/6-311+G(2d,p) $\left(\mathrm{PCM} \mathrm{CH}_{2} \mathrm{Cl}_{2}\right){ }^{1} \mathrm{H}$ NMR spectra for the two diastereomers. ${ }^{[37]}$ In addition, the complete stereoselectivity was further supported by the computational characterization of the four diastereomeric cyclization transition states between $\mathbf{1 1} \mathbf{g}$ and $\mathbf{1 2} \mathbf{g}$, finding that the transition state responsible for the formation of the trans isomer is about $1.86 \mathrm{kcal} \mathrm{mol}^{-1}$ lower in energy than the lowest energy TS leading to the cis product. ${ }^{[37]}$ Later on, this initial assumption was confirmed by $\mathrm{X}$ ray analysis. ${ }^{[38]}$<smiles>[R]c1cc(OC)c([R1])c(OC(c2ccccc2)C([R])([R])O)c1</smiles><smiles>COc1ccc2c(c1OC)OC(c1ccccc1)C2(c1ccccc1)c1ccccc1</smiles>

12a $(A, 81 \%)$<smiles>COc1ccc2c(c1OC)OC(c1ccccc1)C2(C1CC1)C1CC1</smiles>

12c (B, 87\%)

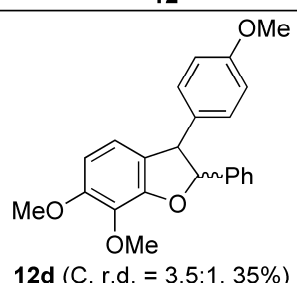<smiles>COc1cc(OC)c2c(c1)OC(c1cccs1)C2(C)c1ccccc1</smiles>

Method A: DNBSA (10 mol\%), MeCN, reflux

Method B: $\mathrm{FeCl}_{3}\left(15 \mathrm{~mol}^{2}\right), \mathrm{AgSbF}_{6}(45 \mathrm{~mol} \%), \mathrm{DCE}, 50^{\circ} \mathrm{C}$ Method C: $\mathrm{Hg}(\mathrm{OTf})_{2}(1 \mathrm{~mol} \%)$, toluene, reflux possessing an electron-rich aromatic ring and an activated secondary or tertiary hydroxyl group in their structure, we intended to carry out an intramolecular Friedel-Crafts reaction that would lead to 2,3-dihydrobenzo[b]furan derivatives 12 (Scheme 8 ). The direct nucleophilic substitution of $\pi$-activated alcohols to build $\mathrm{C}-\mathrm{X}$ or $\mathrm{C}-\mathrm{C}$ bonds is nowadays a wellestablished methodology that avoids the transformation of hydroxyl groups into the corresponding halides or sulfonates for reacting with nucleophiles. ${ }^{[32]}$ Different Lewis and Brønsted acidcatalyzed procedures have been developed in the last years for this reaction, which in the case of using aromatic groups as the nucleophilic partner could be considered catalytic Friedel-Crafts reactions. ${ }^{[33]}$ Taking advantage of our previous experience in this field, ${ }^{[34]}$ we decided to use a simple Brønsted acid like 2,4dinitrobenzenesulfonic acid (DNBSA) as catalyst for attempting the cyclization of a selection of alcohols 11 . Satisfactory results were obtained for starting compounds $\mathbf{1 1 a , c , g , h}$ bearing tertiary highly activated hydroxyl groups, which led to the corresponding

Scheme 8. Synthesis of dihidrobenzo[b]furan derivatives 12.

\section{Conclusions}

In summary, we have demonstrated that aryl benzyl ethers can be selectively $\alpha$-lithiated and, by controlling the reaction temperature, the resulting aryl $\alpha$-lithiobenzyl ethers resulted to be stable enough to prevent the expected, and previously described, [1,2]-Wittig rearrangement. Besides, we have studied the stability of a series of ethers functionalized at the aryl ring towards the Wittig rearrangement. DFT calculations reveal that two mechanisms for this rearrangement can coexist: homolytic cleavage of the $\mathrm{Ar}-\mathrm{O}$ and barrierless recombination of the resultant radicals, and attack of the benzylic anion to the aryl group concerted with $\mathrm{Ar}-\mathrm{O}$ cleavage. Electron rich aryls favor 
the radical path and electron poor aryls the concerted anionic one. As the electronic effect is much larger in the latter, the easiest rearrangements are found for electron poor aryl groups, in agreement with the experimental data. A chelate effect explains the unexpectedly different reactivity of 4-methoxyphenyl and 2-methoxyphenyl ethers. The easy preparation of these $\alpha$ lithiated aryl benzyl ethers has allowed the study of their reactivity towards different electrophiles. In this way, a wide variety of $\alpha$-functionalized aryl benzyl ethers has been accessed including their efficient oxidative coupling with hexacloroethane. Interestingly, their reactions with carboxylic esters lead to ketones, instead of the expected tertiary alcohols, likely due to the fast generation of the corresponding enolate. Moreover, further reactions of some of the obtained compounds has led to the diastereselective synthesis of mono-protected of 1,2diarylethane-1,2-diols and dihydrobenzo[b]furan derivatives.

\section{Experimental Section}

Typical procedure for the synthesis of $\alpha$-funtionalized aryl benzyl ethers 6-8, and 11. Synthesis of 1-(2-chlorophenyl)-2-phenoxy-2phenylethanone (8ac): To an oven dried Schlenck flask under $\mathrm{N}_{2}$ anhydrous THF $(2.5 \mathrm{~mL})$ and ether $1 \mathbf{a}(92 \mathrm{mg}, 0.5 \mathrm{mmol})$ were added. This solution is cooled to $-78{ }^{\circ} \mathrm{C}$ and then $\mathrm{tBuLi}(0.38 \mathrm{~mL}$ of a $1.7 \mathrm{M}$ solution in pentane, $0.65 \mathrm{mmol}$ ) was added. The mixture was stirred for $20 \mathrm{~min}$ at this temperature. Then, ethyl 2-chorobenzoate $(120 \mathrm{mg}, 0.65$ $\mathrm{mmol}$ ) was added, and after $5 \mathrm{~min}$, the cooling bath was removed, allowing the reaction mixture to warm up to RT. Finally, the reaction mixture was quenched with $\mathrm{H}_{2} \mathrm{O}(15 \mathrm{~mL})$ and extracted with $\mathrm{Et}_{2} \mathrm{O}(3 \times 10$ $\mathrm{mL}$ ). The organic layers were combined, dried over anhydrous $\mathrm{NaSO}_{4}$ and concentrated in vacuo. The residue was purified by flash chromatography on silica gel using hexane:EtOAc $(15: 1)$ as eluent to afford ketone $8 \mathrm{ac}(116 \mathrm{mg}, 72 \%)$ as a colorless oil; $R_{\mathrm{f}}=0.24$ (hexane/EtOAc $=15 / 1) ;{ }^{1} \mathrm{H} \mathrm{NMR}\left(300 \mathrm{MHz}, \mathrm{CDCl}_{3}, 25^{\circ} \mathrm{C}\right): \delta=7.50-7.43$ (m, 2H), 7.40-7.30 (m, 5H), 7.29-7.20 (m, 4H), 7.00-6.92 (m, 3H), 6.32 (s, $1 \mathrm{H}) \mathrm{ppm} ;{ }^{13} \mathrm{C}$ NMR $\left(75.4 \mathrm{MHz}, \mathrm{CDCl}_{3}, 25^{\circ} \mathrm{C}\right): \delta=198.9(\mathrm{C}), 157.4(\mathrm{C})$ $137.2(\mathrm{C}), 134.9(\mathrm{C}), 131.9(\mathrm{CH}), 131.2(\mathrm{C}), 130.3(\mathrm{CH}), 129.6(2 \times \mathrm{CH})$, $129.5(\mathrm{CH}), 129.0(2 \times \mathrm{CH}), 128.98(\mathrm{CH}), 127.5(2 \times \mathrm{CH}), 126.6(\mathrm{CH})$, $121.9(\mathrm{CH}), 116.1(2 \times \mathrm{CH}), 84.5(\mathrm{CH}) \mathrm{ppm}$; LRMS(EI): $\mathrm{m} / \mathrm{z}(\%): 183$ $\left[\left(\mathrm{M}-\mathrm{C}_{7} \mathrm{H}_{4} \mathrm{ClO}\right)^{+}, 100\right], 155$ (31), 77 (25); HRMS (EI) calcd for $\mathrm{C}_{20} \mathrm{H}_{15} \mathrm{ClO}$ : 322.0761; found: 322.0757 .

\section{Acknowledgements}

We gratefully acknowledge the Junta de Castilla y León and FEDER (BU237U13 and BU076U16) and Ministerio de Economía y Competitividad (MINECO) and FEDER (CTQ201348937-C2-1P and 2-P) for financial suport. R.V. thanks Junta de Castilla y León (Consejería de Educación) and Fondo Social Europeo for a PIRTU contract. We also thank the Centro de Supercomputación de Galicia (CESGA) for the allocation of computational resources.

Keywords: lithiation $\cdot$ Wittig rearrangement $\cdot$ computational methods $\cdot$ reaction mechanisms $\cdot$ oxygen heterocycles
[1] a) J. A. Marshall in Comprehensive Organic Synthesis, Vol. 3 (Eds.: B M. Trost, I. Fleming), Pergamon Press, Oxford, 1991, pp. 975-1014; b) K. Tomooka, H. Yamamoto, T. Nakai, Liebigs Ann./Recueil 1997, 1275-1281; c) K. Tomooka in The Chemistry of Organolithium Compounds, Vol. 1 (Eds.: Z. Rappoport, I. Marek), Wiley, London, 2004, pp. 749-828.

[2] G. Wittig, L. Löhmann, Justus Liebigs Ann. Chem. 1942, 550, 260-268.

[3] J. S. Swayer, T. L. Macdonald, G. J. McGarvery, J. Am. Chem. Soc 1984, 106, 3376-3377.

[4] F. M. Perna, A. Salomone, V. Capriati in Lithium Compounds in Organic Synthesis: From Fundamentals to Applications (Eds.: R. Luisi, V. Capriati), Wiley-VCH, Weinheim, 2014, ch. 6, pp. 153-190. For other, $\alpha$-oxygen-substituted compounds, see for instance: a) D. I. Coppi, A. Salomone, F. M. Perna, V. Capriati, Chem. Commun. 2011, 47, 9918-9920; b) R. Mansueto, V. Mallardo, F. M. Perna, A. Salomone, V. Capriati, Chem. Commun. 2013, 49, 10160-10162.

[5] a) U. Schölkopf, Angew. Chem. 1970, 82, 795-805; Angew. Chem. Int. Ed. 1970, 9, 763-773; b) J. F. Garst, C. D. Smith, J. Am. Chem. Soc 1976, 98, 1526-1537; c) P. Antoniotti, G. Tonachini, J. Org. Chem. 1998, 63, 9756-9762.

[6] For selected synthetic applications of the [1,2]-Wittig rearrangement, see: a) K. Tomooka, H. Yamamoto, T. Nakai, J. Am. Chem. Soc. 1996 118, 3317-3318; b) K. Tomooka, K. Yamamoto, T. Nakai, Angew. Chem. 1999, 111, 3955-3957; Angew. Chem. Int. Ed. 1999, 38 3741-3743; c) K. Tomooka, H. Yamamoto, T. Nakai, Angew. Chem. 2000, 112, 4674-4676; Angew. Chem. Int. Ed. 2000, 39, 4500-4502; d) O. Kitagawa, S.-i. Momose, Y. Yamada, M. Shiro, T. Taguchi, Tetrahedron Lett. 2001, 42, 4865-4868; e) V. Capriati, S. Florio, G. Ingrosso, C. Granito, L. Troisi, Eur. J. Org. Chem. 2002, 478-484; f) M. B. Bertrand, J. P. Wolfe, Org. Lett. 2006, 8, 4661-4663; g) T. Nakano, T. Soeta, K. Endo, K. Inomata, Y. Ukaji, J. Org. Chem. 2013, 78, 12654-12661; h) L. M. Mori-Quiroz, R. E. Maleczka, Jr., J. Org. Chem. 2015, 80, 1163-1191.

[7] a) V. Rautenstrauch, G. Büchi, H. Wüest, J. Am. Chem. Soc. 1974, 96, 2576-2580; b) K. Tomooka, T. Inoue, T. Nakai, Chem. Lett. 2000 418-419; c) F. Kurosawa, T. Nakano, T. Soeta, K. Endo, Y. Ukaji, J. Org. Chem. 2015, 80, 5696-5703.

[8] a) J. J. Eisch, C. A. Kovacs, S.-G. Rhee, J. Organomet. Chem. 1974, 65, 289-301; b) S.-i. Kiyooka, T. Tsutsui, T. Kira, Tetrahedron Lett. 1996, 37, 8903-8904; c) G. Gao, F.-L. Gu, J.-X. Jiang, K. Jiang, C.-Q. Sheng, G.-Q. Lai, L.-W. Xu, Chem. Eur. J. 2011, 17, 2698-2703. For related [1,2]-anionic rearrangements of pyridyl ethers, see: d) J. Yang, G. B. Dudley, J. Org. Chem. 2009, 74, 7998-8000; e) J. Yang, G. B. Dudley, Adv. Synth. Catal. 2010, 352, 3438-3442.

[9] S. Strunk, M. Schlosser, Eur. J. Org. Chem. 2006, 4393-4397.

[10] J. Hioe, H. Zipse, Org. Biomol. Chem. 2010, 8, 3609-3617.

[11] a) U. Azzena, S. Demartis, M. G. Fiori, G. Melloni, L. Pisano, Tetrahedron Lett. 1995, 31, 5641-5644; b) A. Krief, J. Bousbaa, Tetrahedron Lett. 1997, 38, 6289-6290.

[12] Inhibition of Wittig rearrangement of alkyl benzyl ethers has been achieved through coordination to chromium tricarbonyl: S. G. Davies, N. J. Holman, C. A. Laughton, B. E. Mobbs, J. Chem. Soc., Chem. Commun. 1983, 1316-1317. For a particular example of intramolecular addition of a metalated benzyl ether to a carbonyl group, see: $\mathrm{M}$ Matsumoto, N. Watanabe, A. Ishikawa, H. Murakami, Chem. Commun. 1997, 2395-2396

[13] J. Barluenga, F. J. Fañanás, R. Sanz, C. Marcos, M. Trabada, M. Org. Lett. 2002, 4, 1587-1590.

[14] R. Sanz, D. Miguel, A. Martínez, A. Pérez, J. Org. Chem. 2006, 71, 4024-4027.

[15] R. Velasco, C. Feberero, R. Sanz, Org. Lett. 2015, 17, 4416-4419.

[16] Starting ethers 1 were prepared via classical Williamson reactions. See Supporting Information for details.

[17] Prolonged reaction times $(5 \mathrm{~h})$ with $\mathbf{1 c}$ led to competitive proton abstraction prior to the rearrangement. 
[18] Gaussian 09, Revision D.01, M. J. Frisch, G. W. Trucks, H. B. Schlegel, G. E. Scuseria, M. A. Robb, J. R. Cheeseman, G. Scalmani, V. Barone B. Mennucci, G. A. Petersson, H. Nakatsuji, M. Caricato, X. Li, H. P. Hratchian, A. F. Izmaylov, J. Bloino, G. Zheng, J. L. Sonnenberg, M. Hada, M. Ehara, K. Toyota, R. Fukuda, J. Hasegawa, M. Ishida, T. Nakajima, Y. Honda, O. Kitao, H. Nakai, T. Vreven, J. A. Montgomery, Jr., J. E. Peralta, F. Ogliaro, M. Bearpark, J. J. Heyd, E. Brothers, K. N Kudin, V. N. Staroverov, R. Kobayashi, J. Normand, K. Raghavachari, A. Rendell, J. C. Burant, S. S. Iyengar, J. Tomasi, M. Cossi, N. Rega, J. M. Millam, M. Klene, J. E. Knox, J. B. Cross, V. Bakken, C. Adamo, J. Jaramillo, R. Gomperts, R. E. Stratmann, O. Yazyev, A. J. Austin, R. Cammi, C. Pomelli, J. W. Ochterski, R. L. Martin, K. Morokuma, V. G. Zakrzewski, G. A. Voth, P. Salvador, J. J. Dannenberg, S. Dapprich, A D. Daniels, Ö. Farkas, J. B. Foresman, J. V. Ortiz, J. Cioslowski, and D. J. Fox, Gaussian, Inc., Wallingford CT, 2009.

[19] a) S. Grimme, J. Antony, S. Ehrlich, H. Krieg, J. Chem. Phys. 2010, 132, 154104; b) S. Grimme, S. Ehrlich, L. Goerigk, J. Comput. Chem. 2011 32, 1456-1465.

[20] a) H-Kr: A. Schaefer, H. Horn, R. Ahlrichs, J. Chem. Phys. 1992, 97, 2571; b) F. Weigend, R. Ahlrich, Phys. Chem. Chem. Phys. 2005, 7, 3297.

[21] F. Neese, WIREs Comput Mol Sci, 2012, 2, 73-78

[22] J. Tomasi, B. Mennucci, R. Cammi, Chem. Rev. 2005, 105, 2999-3093.

[23] A. Klamt, G. Schüürmann, J. Chem. Soc., Perkin Trans. 21993, 799-805.

[24] Review: a) C. Liu, L. Jin, A. Lei, Synlett 2010, 2527-2536. For recent examples of transition metal-catalyzed coupling of organometallic reagents, see: b) Y. Zhu, T. Xiong, W. Han, Y. Shi, Org. Lett. 2014, 16 6144-6147; c) L.-Y. Liao, K.-M. Liu, X.-F. Duan, J. Org. Chem. 2015, 80, 9856-9867; d) K.-M. Liu, J. Wei, X.-F. Duan, Chem. Commun. 2015 , $51,4655-4658$.

[25] See, for instance: a) A. Krasovskiy, A. Tishkov, V. del Amo, H. Mayr, P. Knochel, Angew. Chem. 2006, 118, 5132-5136; Angew. Chem. Int. Ed. 2006, 45, 5010-5014; b) M. S. Maji, T. Pfeifer, A. Studer, Angew. Chem. 2008, 120, 9690-9692; Angew. Chem. Int. Ed. 2008, 47, 9547-9550; c) T. Amaya, R. Suzuki, T. Hirao, Chem. Eur. J. 2014, 20, 653-656.

[26] M. Blangetti, P. Fleming, D. F. O'Shea, J. Org. Chem. 2012, 77, 2870-2877.

[27] S. H. Goh, R. L. Huang, S. H. Ong, I. Sieh, J. Chem. Soc. (C) 1971 , 2282-2296. Alternative routes to O,O-dialkyl 1,2-diphenylethane diols involving reductive coupling of aromatic dialkyl acetals have not been applied to the corresponding diaryl acetals: B. Hatano, K. Nagahashi, S. Habaue, Chem. Lett. 2007, 36, 1418-1419.

[28] H.-G. Heine, Tetrahedron Lett. 1972, 47, 4755-4758.

[29] S. H. Goh, S. H. Ong, I. Sieh, Org. Mag. Res. 1971, 3, 713-720.

[30] N. Bajwa, M. P. Jennings, J. Org. Chem. 2008, 73, 3638-3641.

[31] J. Yin, M. A. Huffman, K. M. Conrad, J. D. Armstrong, III, J. Org. Chem. 2006, 71, 840-843.

[32] Reviews: a) E. Emer, R. Sinisi, M. Guiteras Capdevila, D. Petruzziello, F. De Vincentiis, P. G. Cozzi, Eur. J. Org. Chem. 2011, 647-666; b) M. Bandini, M. Tragni, Org. Biomol. Chem. 2009, 7, 1501-1507; c) R. Kumar, E. V. Van der Eicken, Chem. Soc. Rev. 2013, 42, 1121-1146; d) M. Dryzhakov, E. Richmond, J. Moran, Synthesis 2015, 48, 935-959.

[33] For examples of catalytic intramolecular Friedel-Crafts reactions with alcohols, see: a) W. Huang, P. Zheng, Z. Zhang, R. Liu, Z. Chen, X. Zhou, J. Org. Chem. 2008, 73, 6845-6848; b) M. Bandini, M. Tragni, A. Umani-Ronchi, Adv. Synth. Catal. 2009, 351, 2521-2524; c) S. Kumar Das. R. Singh, G. Panda, Eur. J. Org. Chem. 2009, 4757-4761; d) S. Sarkar, S. Maiti, K. Bera, S. Jalal, U. Jana, Tetrahedron Lett. 2012, 53, 5544-5547; e) J. Panteleev, R. Y. Huang, E. K. J. Liu, M. Lautens, Org. Lett. 2011, 13, 5314-5317; f) B. Nammalwar, R. A. Bunce, Tetrahedron Lett. 2013, 54, 4330-4332; g) F.-Z. Zhang, Y. Tian, G.-X. Li, J. Qu, J. Org. Chem. 2015, 80, 1107-1115.

[34] a) R. Sanz, A. Martínez, J. M. Álvarez-Gutiérrez, F. Rodríguez, Eur. J. Org. Chem. 2006, 1383-1386; b) R. Sanz, A. Martínez, D. Miguel, J. M. Álvarez-Gutiérrez, F. Rodríguez, Adv. Synth. Catal. 2006, 348 1841-1845; c) R. Sanz, D. Miguel, J. M. Álvarez-Gutiérrez, F. Rodríguez, Synlett 2008, 975-978; d) A. Suárez, M. Gohain, M. A. Fernández-Rodríguez, R. Sanz, J. Org. Chem. 2015, 80, 10421-10430.

[35] For 12c better yield was obtained using the catalytic system $\mathrm{FeCl}_{3} / \mathrm{AgSbF}_{6}$ : L. R. Jefferies, S. P. Cook, Org. Lett. 2014, 16, 2026-2029.

[36] K. Namba, H. Yamamoto, I. Sasaki, K. Mori, H. Imagawa, M. Nishizawa, Org. Lett. 2008, 10, 1767-1770.

[37] See Supporting Information for further details.

[38] CCDC 1478974 (12g) contains the supplementary crystallographic data for this paper. These data can be obtained free of charge from The Cambridge Crystallographic Data Centre via www.ccdc.cam.ac.uk/data_request/cif. 
Entry for the Table of Contents (Please choose one layout)

Layout 2:

\section{FULL PAPER}

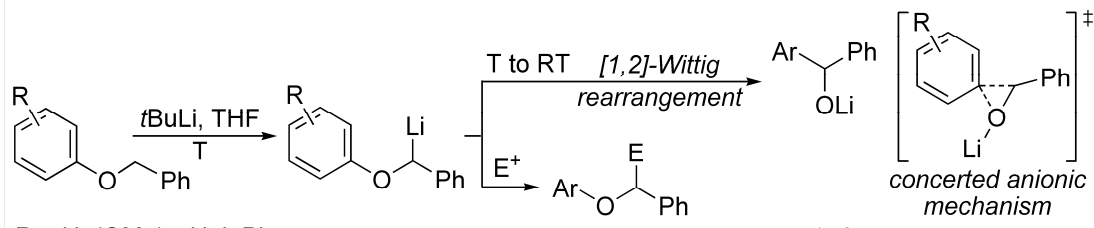

$\mathrm{R}=\mathrm{H},(\mathrm{OMe})_{\mathrm{n}}, \mathrm{Hal}, \mathrm{Ph}, .$.
Rocío Velasco, Carlos Silva-López, Olalla Nieto-Faza, ${ }^{*}$ and Roberto Sanz ${ }^{\star}$

Page No. - Page No.

Exploring the Reactivity of $\alpha$-Lithiated Aryl Benzyl Ethers: Inhibition of the [1,2]-Wittig Rearrangement and Revisited Mechanistic Proposal

A full account for the selective $\alpha$-lithiation of aryl benzyl ethers is reported. By a careful control of reaction temperature, aryl $\alpha$-lithiobenzyl ethers are stable enough to be trapped by a wide variety of electrophiles leading to functionalized ethers. The mechanism of the expected [1,2]-Wittig rearrangement in these $\alpha$-oxygensubstituted organolithiums is discussed based on DFT calculations. 